\title{
KNOWLEDGE GRID MODEL IN FACILITATING KNOWLEDGE SHARING AMONG BIG DATA COMMUNITY
}

\author{
Sara Hosseinioun \\ Faculty of Computer Science and Information Technology, University Putra Malaysia. \\ *Corresponding Author Email: sarahosseinioun@gmail.com
}

This is an open access article distributed under the Creative Commons Attribution License, which permits unrestricted use, distribution, and reproduction in any medium, provided the original work is properly cited.

\section{ARTICLE DETAILS}

Article History:

Received 12 December 2017

Accepted 10 January 2018

Available online 19 February 2018

\section{ABSTRACT}

Now days big data become one of the most interesting area in research and this study focus on the inefficiency of knowledge sharing among big data community. Moreover, it reviews current knowledge grid models and the way they can improve knowledge sharing through big data community while knowledge grid structure is for dealing with huge amount of data.

\section{KEYWORDS}

Knowledge sharing, big data, knowledge grid, grid models

\section{INTRODUCTION}

While technology revolution makes generating enormous data simple for digital devices users all over the world and this phenomenon has extended swiftly and ever-increasing scale which called big data. The scale is not the only issue for managing these massive generated data, since it involves a great variety of data forms such as text, sound, video etc., and time as other dimension of data stream [1]. Big data community have been defined as strength relationship between community members as decision maker service providers or social media users which can be individuals or organizations while huge amount and variety of storage knowledge flow among them around the world. These members join to the community from variety areas such as health and human welfare, business and commerce, government and public services, science and education, social media and etc. to discuss, give advice, collaborate and exchange knowledge and sources to improve their decision making, services and products Moreover, knowledge grid is a communication infrastructure which obtains, represents and exchanges effectively massive data and information while integrates and converts them into useful knowledge through mining and reference methods [2]. It can modify distribute knowledge between big data community members by using Grid Computing for its high storage capability and processing power and Grids were originally designed for dealing with problems involving large amounts of data or compute-intensive applications $[3,4]$.

\section{METHODS}

The research aimed to identify issues of knowledge sharing in big data community and highlight currents knowledge grid's models among big data [5]. Analysis of results revealed difficulty of knowledge sharing between community members' interaction and collaboration and there is gap in researches on sharing efficiency through the big data community Moreover, knowledge grid as communication infrastructure can effectively acquires, represents and exchanges massive amount of knowledge however current knowledge grid models focus on knowledge accessibility through big data and there is lack of efficient knowledge grid model for distributing knowledge among community members by considering their satisfaction [6].

\section{RESULTS AND DISCUSSIONS}

The research has been reviewed the difficulty of converting raw data to understandable knowledge and share it among big data community members. This community is based on regular interaction, a common objective, relationships and communication between the users as individuals and organizations from different areas such as Medical, Business, Education and etc., thus, facilitating knowledge flow between members is significant [7]. Big data characteristics makes finding valuable information among increasing rate of data, flow and distribute it between users at real time complicated [1]. Table 1 shows there is difficulty of knowledge sharing through the big data community while it characteristics have direct impact of knowledge accessibility, reliability, validity, security and privacy which lack of them cause inefficient knowledge sharing among this community. So current situation of knowledge sharing in big data chaos have significant distance from facilitating.

Table 1: Knowledge sharing challenges among big data community

\begin{tabular}{|lccccc|}
\hline References & $\begin{array}{l}\text { Accessibi } \\
\text { Ity }\end{array}$ & $\begin{array}{l}\text { Reliabil } \\
\text { ty }\end{array}$ & validity & security & privacy \\
\hline$[14]$ & & $\mathrm{X}$ & $\mathrm{X}$ & $\mathrm{X}$ & $\mathrm{X}$ \\
{$[1]$} & $\mathrm{X}$ & $\mathrm{X}$ & & & \\
{$[7]$} & & & & $\mathrm{X}$ & $\mathrm{X}$ \\
{$[5]$} & $\mathrm{X}$ & $\mathrm{X}$ & & & \\
{$[8]$} & & $\mathrm{X}$ & $\mathrm{X}$ & $\mathrm{X}$ & \\
{$[9]$} & & $\mathrm{X}$ & $\mathrm{X}$ & & $\mathrm{X}$ \\
{$[12]$} & $\mathrm{X}$ & $\mathrm{X}$ & & $\mathrm{X}$ & \\
\hline Total & 3 & 6 & 3 & 4 & 3 \\
\hline
\end{tabular}

In addition, knowledge grid as dynamic distribute system, connected knowledge around worldwide and guaranteed proper knowledge clustering as a minimum complete knowledge set for solving problems. To achieve this goal, it needs to create new knowledge organization models by finding the semantic relationship in collected knowledge which isn't statically stored [5-10]. In Grid number of servers are interconnected by high speed network, which each server plays one many roles trough the grid. It will help to increase storage capability which is so important in big data [6, 11-17]. The Table 2 illustrate current Knowledge grid model and their focus and gap through big data community. 
Table 2: Current Knowledge Grid models focus and Gap

\begin{tabular}{|c|c|c|}
\hline Author & Focus & Gap \\
\hline$[4]$ & Accessibility, Reliability and Security & Validity and Privacy \\
\hline$[13]$ & Accessibility and Reliability & Security, Validity and Privacy \\
\hline$[17]$ & Accessibility, Security and Privacy & Reliability and Validity \\
\hline
\end{tabular}

\section{CONCLUSION}

The research highlights issues of knowledge sharing in big data community as massive volume of both structured and unstructured data which are interconnected by considering user and organizations expectation as member of community. Knowledge Grid as dynamic distributing system which can handle massive data processing and storage facilitate knowledge sharing. However, there is issue in accessibility, reliability, validity, security and privacy of shared knowledge among the community which decrease the efficiency of knowledge sharing and user satisfaction. Also, current knowledge grid models focused on knowledge clustering among big data and it accessibility and there is a lack of model to consider all the factors which facilitate knowledge sharing.

\section{REFERENCES}

[1] Che, D., Safran, M., Peng, Z. 2013. From Big Data to Big Data Mining: Challenges, Issues, and Opportunities. DASFAA, 7827 (1), 1-15.

[2] Mahamud, K., Ruhana, K. 2013. Big Data Clustering Using Grid Computing and Ant-Based Algorithm. Sarawak, Malaysia, 4th International Conference on Computing and Informatics.

[3] Aminu, L.M. 2014. Implementing Big Data Management on Grid Computing Environment. International Journal of Engineering And Computer Science, 3 (9), 8455-8459.

[4] Cesario, E., Congiusta, A., Talia, D., Trunfio, P. 2007. Designing data analysis services in the Knowledge Grid. CoreGRID, 1-15.

[5] Sivarajah, U., Kamal, M.M., Irani, Z., Weerakkody, V. 2017. Critical analysis of Big Data challenges and analytical methods. Journal of Business Research, 70, 263-286.

[6] Fredriksson, C. 2015. Knowledge Management with Big Data Creating New Possibilities for Organizations. Gothenburg, Nordiska kommunforskarkonferensen.

[7] Al-Nuaimi, E., Al-Neyadi, H., Mohamed, N., Al-Jaroodi, J. 2015 Applications of big data. Journal of Internet Services and Applications, 6 (1), 1-15.
[8] Chandhini, C., Megana, L.P. 2013. Grid Computing-A Next Level Challenge with Big Data. International Journal of Scientific and Engineering Research, 4 (3), 1-5.

[9] Chen, C.J., Hung, S.W. 2012. To give or to receive? Factors influencing members' knowledge sharing and community promotion in professional virtual communities. Information and Management, 47, 226-236.

[10] Chen, C.L.P., Zhang, C.Y. 2014. Data-intensive applications, challenges, techniques and technologies: A survey on Big Data. Information Sciences, 275 (1), 314-347.

[11] Dong, X., Li, R., He, H., Zhou, W., Xue, Z., Wu, H. 2015. Secure Sensitive Data Sharing on a Big Data Platform. Tsinghua Science and Technology, 20 (1), 72-80.

[12] Garlasu, D., Sandulescu, V., Halcu, L., Neculoiu, G., Grigoriu, O., Marinescu, M., Marinescu, V. 2013. A Big Data implementation based on Grid Computing. Sinala, 11th Roedunet International Conference (RoEduNet).

[13] Hendriks, P. 1999. Why share knowledge? The influence of ICT on the motivation for knowledge sharing. Knowledge and Process Management, 6 (2), 91-100.

[14] Hsiao, C.C., Chiou, J.S. 2012. The impact of online community position on online game continuance intention: Do game knowledge and community size matter?, Information and Management, 49,292-300.

[15] Wang, G., Wen, T., Guo, Q., Ma, X. 2006. A Knowledge Grid Architecture Based on Mobile Agent. Washington, DC, USA, IEEE.

[16] Zhuge, H., Sun, X. 2016. Semantics, Knowledge and Grids on Big Data. Future Generation Computer Systems, 64,163-164.

[17] Zhuge, H. 2002. A Knowledge grid model and platform for global knoeledge sharing. Expert systems with Applications, 22, 313-320.

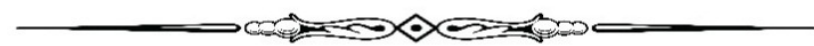

